This item was submitted to Loughborough's Research Repository by the author.

Items in Figshare are protected by copyright, with all rights reserved, unless otherwise indicated.

\title{
In situ monitoring of latex film formation by small-angle neutron scattering: Evolving distributions of hydrophilic stabilizers in drying colloidal films
}

\section{PLEASE CITE THE PUBLISHED VERSION}

https://doi.org/10.1021/acs.langmuir.8b04251

\section{PUBLISHER}

(C) American Chemical Society (ACS)

\section{VERSION}

AM (Accepted Manuscript)

\section{PUBLISHER STATEMENT}

This document is the Accepted Manuscript version of a Published Work that appeared in final form in Langmuir, copyright $\odot$ American Chemical Society after peer review and technical editing by the publisher. To access the final edited and published work see https://doi.org/10.1021/acs.langmuir.8b04251

\section{LICENCE}

CC BY-NC-ND 4.0

\section{REPOSITORY RECORD}

Martin-Fabiani, Ignacio, David K. Makepeace, Philip G. Richardson, Jennifer Lesage de la Haye, Diego Alba Venero, Sarah E. Rogers, Franck D'Agosto, Muriel Lansalot, and Joseph L. Keddie. 2019. "In Situ Monitoring of Latex Film Formation by Small-angle Neutron Scattering: Evolving Distributions of Hydrophilic Stabilizers in Drying Colloidal Films". figshare. https://hdl.handle.net/2134/37396. 


\section{In Situ Monitoring of Latex Film Formation by}

\section{Small-Angle Neutron Scattering (SANS): Evolving}

\section{Distributions of Hydrophilic Stabilizers in Drying}

\section{Colloidal Films}

Ignacio Martín-Fabiani, ${ }^{1, *}$ David K. Makepeace, ${ }^{2}$ Philip G. Richardson, ${ }^{2}$ Jennifer Lesage de la Haye, ${ }^{3}$ Diego Alba Venero, ${ }^{4}$ Sarah E. Rogers, ${ }^{4}$ Franck D'Agosto, ${ }^{3}$ Muriel Lansalot ${ }^{3}$ and Joseph L. Keddie $^{2}$

${ }^{1}$ Department of Materials, Loughborough University, Loughborough LE11 3TU, Leicestershire, United Kingdom

${ }^{2}$ Department of Physics, University of Surrey, Guildford GU2 7XH, United Kingdom

${ }^{3}$ Univ Lyon, Université Claude Bernard Lyon 1, CPE Lyon, CNRS, UMR 5265, Chemistry, Catalysis, Polymers and Processes (C2P2), 43 Bd du 11 Novembre 1918, 69616 Villeurbanne, France

${ }^{4}$ ISIS Pulsed Neutron and Muon Source, Science and Technology Facilities Council, Rutherford Appleton Laboratory, Harwell, Oxford, Didcot OX11 0QX, United Kingdom 
Keywords: surfactant; waterborne; macroRAFT; small-angle neutron scattering; latex; free energy; interfacial energy

\section{ABSTRACT}

The distribution of hydrophilic species, such as surfactants, in latex films is of critical importance for the performance of adhesives, coatings and inks, among others. However, the evolution of this distribution during the film formation process and in the resulting dried films remains insufficiently elucidated. Here, we present in situ (wet) and ex situ (dry) SANS experiments that follow the film formation of two types of latex particles, which differ in their stabilizer: either a covalently bonded poly(methacrylic acid) (PMAA) segment or a physically adsorbed surfactant (sodium dodecyl sulfate, SDS). By fitting the experimental SANS data and combining with gravimetry experiments, we have ascertained the hydrophilic species distribution within the drying film and followed its evolution by correlating the size and shape of stabilizer clusters with the drying time. The evolution of the SDS distribution over drying time is being driven by a reduction in the interfacial free energy. However, the PMAA-based stabilizer macromolecules are restricted by their covalent bonding to core polymer chains and hence form high surface-area disc-like phases at the common boundary between particles and PMAA micelles. Contrary to an idealized view of film formation, the PMAA does not remain in the walls of a continuous honeycomb structure. The results presented here shed new light on the nanoscale distribution of hydrophilic species in drying and ageing latex films. We provide valuable insights into the influence of the stabilizer mobility on the final structure of latex films. 


\section{INTRODUCTION}

When colloidal polymer particles in water (also known as latex) are deposited onto a substrate to form a film, the complex process that takes place can be divided into several steps. First, water evaporates to bring the particles into close packing. Then, in order to reduce the interfacial free energy and under the action of capillary pressure, particles deform to fill the gaps between them. Finally, the boundaries between the particles disappear as a result of the polymer chain diffusion, ideally resulting in a homogeneous film. Although extensive work has been carried out to understand and control latex film formation, ${ }^{1}$ there are aspects of the process that remain insufficiently explored.

One poorly understood topic is the final distribution of particle stabilizers, such as surfactants, and their evolution during the film formation process. These hydrophilic molecules are physically adsorbed to the surface of the latex particle and therefore can migrate during film formation, resulting in an inhomogeneous distribution throughout the dried film. Such inhomogeneities can be detrimental to certain film properties. For example, the accumulation of surfactant at the top of the film increases its tackiness and reduces gloss. ${ }^{2}$ Adhesive properties, such as peel strength, are strongly dependent on the surfactant type and concentration, ${ }^{3,4}$ and surfactants are found at the locus of failure. ${ }^{5}$ Moreover, the presence of surfactants has been found to have a negative impact on films' barrier properties when exposed to liquid water ${ }^{6}$ or vapor. ${ }^{7}$

As a result of the relevance of this problem, many works have been devoted to the study of the distribution of surfactant in dried latex films. Vertical profiles acquired using Rutherford backscattering $^{8}$ and confocal Raman spectroscopy, ${ }^{9,10}$ as well as surface measurements using Fourier transform infra-red-attenuated total reflection (FTIR-ATR),${ }^{11}$ have provided evidence for an enrichment of surfactant at the top film layer when compared with the bulk. However, these 
techniques do not usually provide information about the size and morphology of the surfactant aggregates. At a local scale, they have been observed using confocal Raman spectroscopy, ${ }^{12}$ atomic force microscopy (AFM) ${ }^{13}$ and transmission electron microscopy (TEM) ${ }^{14}$. To obtain representative information of the overall film, it is best to employ scattering techniques, which in transmission can provide information over areas on the order of $\mathrm{mm}^{2}$ and throughout the whole thickness of the film under study. In addition, scattering can be used to follow in situ formation of the latex film. Hu et al. used small-angle X-ray scattering (SAXS) to monitor the first two stages of latex film formation, i.e. water evaporation/particle packing and particle deformation. ${ }^{15}$ In another work by the same group, they followed the annealing process, identifying a percolating cellular structure that they attributed to emulsifier and salts located at the outer layer of the particles. As the annealing temperature increased, cell wall disruption started to take place, eventually leading to expulsion of emulsifier and salts and agglomeration in clusters. ${ }^{16}$ In a later work on annealed latex films, Chen et al. ${ }^{17}$ proposed a sphere model to describe the surfactant aggregates. However, this representation did not fit adequately the data in the range of low scattering vector, $\vec{q}$, indicating that a more complete model is needed for describing the different (nano)structures present in latex films.

The use of contrast variation in small-angle neutron scattering (SANS) allows changing the contrast of different components of the ensemble through deuteration. In particular it has been proved very useful to increase the contrast of the surfactant, allowing researchers to ascertain its distribution in latex films. Joanicot et al. ${ }^{18}$ performed SANS experiments on dried films made from latex with a hydrophilic poly(acrylic acid) (PAA) shell, which led to a cellular structure. After they annealed the films at different temperatures and then rehydrated with $\mathrm{D}_{2} \mathrm{O}$, they found that the cell walls become fragmented as the annealing temperature increases above the PAA glass transition 
temperature. The shells were expelled and formed aggregates within the polymer matrix. When monitoring the formation of partially dried films containing deuterated surfactants, Belaroui et al. likewise detected the disappearance of the cellular structure, which they interpreted as surfactant desorption. ${ }^{19}$ Nevertheless, their analysis does not provide information about the distribution of surfactant after the cellular structure disruption.

To avoid the deleterious effects of surfactants on the final film properties, different synthesis strategies to produce surfactant-free latex particles have been proposed, including the use of polymerizable surfactants..$^{20,21}$ One of the most recent and successful approaches relies on polymerization-induced self-assembly (PISA), associated with reversible addition-fragmentation chain transfer (RAFT) to mediate emulsion polymerization. ${ }^{22-24}$ In this approach, well-defined hydrophilic polymers synthesized by RAFT (macroRAFT) carrying a reactive chain-end are used for the polymerization of hydrophobic monomers in water to produce in situ amphiphilic block copolymers able to act as stabilizers. We recently reported the synthesis of latex particles inspired by this method and minimized the amount of hydrophilic macroRAFT down to 1 wt. $\%{ }^{25,26}$ In a subsequent publication, we also proved that films made from poly(methyl methacrylate-co- $n$-butyl acrylate) particles stabilized by poly(methacrylic acid) (PMAA) chains have better water barrier properties when compared with films obtained from particles with the same monomer composition but stabilized by charges coming from methacrylic acid introduced as a comonomer. ${ }^{27}$ This stands as strong evidence for considering the bonding and mobility of the particle stabilizers to be key in the development of their final distribution in the dried film, which then determines the final properties. In an idealized view of film formation from core-shell particles, the shell creates the walls of a percolating honeycomb structure in the final film. ${ }^{1}$ Surprisingly, the internal structure of films made from this new type of surfactant-free particle has not been explored in detail yet. 
The exception is a SAXS study by Chenal et al., which showed how the cellular structure created by particles of self-assembled amphiphilic block copolymers undergoes a phase inversion into isolated domains upon annealing. ${ }^{28} \mathrm{~A}$ key question is whether the hydrophilic macroRAFT particle stabilizers will create a percolating honeycomb-like structure upon film formation.

Here, we have performed in situ SANS experiments to follow the latex film formation of two types of latex particles. For that purpose, deuterated PMAA (d-PMAA) macroRAFT was first synthesized and used to mediate the emulsion copolymerization of $n$-butyl acrylate (BA) and methyl methacrylate (MMA). The stabilizer in this case is the in situ formed d-PMAA- $b$-P(BAco-MMA) amphiphilic block copolymers thus covalently anchored to the core polymer chains. A similar latex was also produced using deuterated SDS (d-SDS) that is only physically adsorbed on the final particles, and thus expected to have a larger degree of mobility when compared with the d-PMAA chains in the self-stabilized latex. For these two latexes, we present a thorough study of the structural evolution that takes place during all stages of the film formation process (both wet and dry films), providing quantitative information about the morphology of the stabilizer aggregates. We propose a model to fit the experimental results in a more complete way than presented in previous studies on similar systems. This work provides valuable insights into the influence of the stabilizer mobility on the final structure of latex films and, by extension, on their properties.

\section{EXPERIMENTAL}

\section{Materials.}

n-Butyl acrylate (BA, Acros Organics, 99\%), methyl methacrylate (MMA, Acros Organics, 99\%), methacrylic acid-d $\mathrm{d}_{5}\left(\mathrm{~d}-\mathrm{MAA}\right.$, Polymer Source, $>98$ atom \% D), sodium dodecyl-d $\mathrm{d}_{25}$ sulfate (d- 
SDS, Aldrich, $\geq 98$ atom \% D, $\geq 98 \%$ ) and ammonium persulfate (APS, Acros Organics, 98\%) were used as received. Water was deionized before use (Purelab Classic UV, ElgaLab Water).

Syntheses of deuterated latexes. In order to investigate the evolution of the stabilizer distribution during film formation and to correlate it with the enhanced water barrier properties that a less mobile stabilizer provides, ${ }^{27}$ two deuterated latexes were synthesized using stabilizers with different degrees of mobility. The first one was a self-stabilized latex (dPMAA), obtained from macroRAFT-mediated emulsion polymerization as reported elsewhere, ${ }^{26}$ which leads to particles stabilized with deuterated PMAA chains (d-PMAA) that are covalently bonded to the core. The second latex (dSDS) was synthesized via conventional emulsion polymerization using deuterated SDS (d-SDS) as a stabilizer. The stabilizers in both materials were deuterated to increase the contrast with the polymer matrix and follow their structural evolution during the drying process using small-angle neutron scattering (SANS). The procedures of the latex syntheses are presented below and their characteristics are listed in Table 1.

Procedure for the emulsion copolymerizations of BA and MMA mediated by hydrophilic deuterated PMAA macroRAFT agent (dPMAA). The deuterated PMAA macroRAFT agent (dPMAA, $M_{\mathrm{n}}=2600 \mathrm{~g} \mathrm{~mol}^{-1}, D=1.12$ ) was synthesized using deuterated methacrylic acid as described in the literature..$^{29,30}$ The aqueous macroRAFT agent solution was used in the following without further purification. The emulsion polymerization mediated by hydrophilic d-PMAA macroRAFT was performed at $70{ }^{\circ} \mathrm{C}$ in a $100 \mathrm{~mL}$ reactor equipped with a condenser and an anchor-blade stirrer. APS $\left(8.1 \mathrm{mg}, 3.57 \times 10^{-5} \mathrm{~mol}\right)$ was added to a solution of previously synthesized d-PMAA macroRAFT agent $(9.7 \mathrm{wt} \%$ aqueous solution, $1.05 \mathrm{wt} \%$ of d-PMAA based on monomer, bom). Water content was adjusted so that the solids content of the final latex $\tau$ was $\sim 40 \mathrm{wt} \%$ (with $\tau=\left(\mathrm{m}_{0}(\mathrm{BA})+\mathrm{m}_{0}(\mathrm{MMA})\right) / \mathrm{m}_{0}($ latex $\left.)\right)$. The $\mathrm{pH}$ of this solution was adjusted to 
7 with a $1 \mathrm{~mol} \mathrm{~L}^{-1} \mathrm{NaOH}$ aqueous solution. BA (7.2 g, $\left.5.62 \times 10^{-2} \mathrm{~mol}, 60 \mathrm{wt} \% \mathrm{bom}\right)$ and MMA $\left(4.8 \mathrm{~g}, 4.80 \times 10^{-2} \mathrm{~mol}, 40 \mathrm{wt} \% \mathrm{bom}\right)$ were added and the resulting mixture was degassed for 30 min under nitrogen. The polymerization was stopped after $6 \mathrm{~h}$ of stirring and a conversion of $100 \%$ was determined by gravimetry (see Supporting Information).

\section{Procedure for the conventional emulsion copolymerizations of BA and MMA in the presence}

of deuterated SDS (dSDS). dSDS was performed at $70{ }^{\circ} \mathrm{C}$ in a $250 \mathrm{~mL}$ reactor equipped with a condenser and an anchor-blade stirrer. APS (12.5 mg, $\left.5.48 \times 10^{-5} \mathrm{~mol}\right)$ and deuterated SDS (200.0 $\left.\mathrm{mg}, 6.38 \times 10^{-4} \mathrm{~mol}\right)$ were diluted in water $(27.4 \mathrm{~g})$. The $\mathrm{pH}$ of this aqueous solution was adjusted to 7 with $1 \mathrm{~mol} \mathrm{~L}^{-1}$ and $0.1 \mathrm{~mol} \mathrm{~L}^{-1} \mathrm{NaOH}$ aqueous solutions. BA $\left(11.0 \mathrm{~g}, 8.61 \times 10^{-2} \mathrm{~mol}, 60 \mathrm{wt} \%\right.$ bom) and MMA (7.4 g, $\left.7.35 \times 10^{-2} \mathrm{~mol}, 40 \mathrm{wt} \% \mathrm{bom}\right)$ were added and the resulting mixture was degassed for 30 min under nitrogen. The polymerization was stopped after $4 \mathrm{~h}$ of stirring and a conversion of $100 \%$ was determined by gravimetry.

Table 1. Emulsion Copolymerizations of $n$-Butyl Acrylate (BA) and Methyl Methacrylate (MMA) Mediated by Hydrophilic Deuterated PMAA (d-PMAA) MacroRAFT Agent or in the presence of Deuterated SDS (d-SDS).

\begin{tabular}{|c|c|c|c|c|c|c|c|c|c|}
\hline Latex & Monomers $^{a}$ & $\begin{array}{c}\text { wt.\% } \\
\text { stabilizer }^{b}\end{array}$ & $\begin{array}{c}\text { t } \\
\text { (h) }\end{array}$ & $\begin{array}{c}\text { Conv }^{c} \\
(\%)\end{array}$ & $\begin{array}{c}\tau^{d} \\
\text { (wt.\%) }\end{array}$ & $\begin{array}{c}\text { Coag }^{e} \\
\text { (wt.\% } \\
\text { ) }\end{array}$ & $\begin{array}{c}D_{\mathrm{z}}(\mathrm{nm}) / \\
\text { Poly } \\
\text { value }^{f}\end{array}$ & $\underset{g}{\mathbf{p H}_{\mathbf{f}}}$ & $\begin{array}{c}T_{\mathrm{g}}{ }^{h} \\
\left({ }^{\circ} \mathrm{C}\right)\end{array}$ \\
\hline dPMAA & $\begin{array}{c}\text { BA/MMA } \\
(60 / 40)\end{array}$ & $\begin{array}{l}1.05(\mathrm{~d}- \\
\left.\mathrm{PMAA}^{i}\right)\end{array}$ & 6.0 & 100 & 40.7 & 0.25 & $193 / 0.02$ & 6.7 & $\begin{array}{c}-22.5 / \\
+6.9\end{array}$ \\
\hline dSDS & $\begin{array}{c}\text { BA/MMA } \\
(60 / 40)\end{array}$ & $\begin{array}{c}1.09 \text { (d- } \\
\text { SDS) }\end{array}$ & 4.0 & 100 & 40.0 & $j$ & $90 / 0.05$ & 3.7 & -2.9 \\
\hline
\end{tabular}

All the experiments were performed at $70{ }^{\circ} \mathrm{C}$, using $2 \mathrm{mmol} \mathrm{L}^{-1}$ water of ammonium persulfate (APS). The pH was initially adjusted to 7 by addition of a $1 \mathrm{M}$ and $0.1 \mathrm{M} \mathrm{NaOH}$ solutions. ${ }^{a}$ Composition of the initial mixture of hydrophobic monomers. Weight fractions are given in brackets. ${ }^{b}$ With respect to the monomers. ${ }^{c}$ Determined by gravimetry. ${ }^{d}$ Solids content $\tau(\%)=\left(\mathrm{m}_{0-\mathrm{M}}+\mathrm{m}_{0 \text {-stabilizer }}\right) / \mathrm{m}_{0 \text {-total, }}$, with m0-M $_{1}=\mathrm{m}_{0 \text {-BA }}+\mathrm{m}_{0-\mathrm{MMA}}$ and $\mathrm{m}_{0 \text {-stabilizer }}$ $=\mathrm{m}_{0 \text {-d-PMAA }}$ or $\mathrm{m}_{\text {0-d-SDS }}{ }^{e}$ On the basis of the total latex mass. ${ }^{f} D_{\mathrm{z}}$ is the z-average particle diameter and Poly value the dispersity factor determined by dynamic light scattering. ${ }^{g}$ Final $\mathrm{pH}$ of the latex. ${ }^{h}$ Glass transition temperature measured at the midpoint, at $20{ }^{\circ} \mathrm{C} \mathrm{min}{ }^{-1}$. The dPMAA sample presents two glass transition temperatures. ${ }^{i} M_{\mathrm{n}, \mathrm{th}, \mathrm{d}-\mathrm{PMAA}}=2600 \mathrm{~g} \mathrm{~mol}^{-1} D=1.12$, determined by MALDI-TOF. ${ }^{j}$ It was not possible to determine the amount of coagulum because of the too high viscosity of this latex. 
Water loss measurements. The water loss process of dPMAA and dSDS samples was recorded using a digital balance (Sartorius Entris224I-1S) with a resolution of $0.1 \mathrm{mg}$, which was interfaced with a personal computer to register the readings via the SartoCollect software. $400 \mu \mathrm{L}$ of dispersion was cast with a micropipette on quartz substrates $(25.4 \mathrm{~mm} \times 25.4 \mathrm{~mm} \times 1 \mathrm{~mm})$ and left to dry in a temperature-controlled room at $21{ }^{\circ} \mathrm{C}$ and a relative humidity of approximately $50 \%$. The mass of the drying films was recorded every $30 \mathrm{~s}$ until there was no significant change in the value. Film thicknesses at different drying times were calculated using the mass obtained by gravimetry at a specific time and the quartz substrate dimensions. The latex films had thicknesses which varied from typically 500 microns in the initial wet state to 200 microns in the final dry state.

Small-angle neutron scattering (SANS). Neutron scattering experiments were performed at the SANS2D instrument at the ISIS Neutron and Muon Source (Rutherford Appleton Laboratory, Didcot, U.K.). A simultaneous q-range of $0.0015-0.25 \AA^{-1}$ was achieved utilizing an incident wavelength of $1.75-12.5 \AA$ and employing an instrument set up of L1 (sample to detector distance $)=\mathrm{L} 2($ collimation length $)=12 \mathrm{~m}$, with a $1 \mathrm{~m}^{2}$ detector offset vertically $60 \mathrm{~mm}$ and sideways $100 \mathrm{~mm}$. q is defined as the modulus of the scattering vector $\vec{q}$ :

$$
q=\frac{4 \pi \sin \frac{\theta}{2}}{\lambda}
$$

where $\theta$ is the scattered angle and $\lambda$ is the incident neutron wavelength. The beam diameter was 8 $\mathrm{mm}$. Each raw scattering data set was corrected for the detector efficiencies, sample transmission and background scattering and converted to scattering cross-section data $(\partial \Sigma / \partial \Omega$ versus $\mathrm{q})$ using instrument-specific software. ${ }^{31}$ These data were placed on an absolute scale $\left(\mathrm{cm}^{-1}\right)$ using the scattering from a standard sample (a solid blend of hydrogenous and perdeuterated polystyrene) in 
accordance with established procedures. ${ }^{32}$ The initial latex dispersions were measured as a reference in Hellma quartz banjo cells of $1 \mathrm{~mm}$ path length.

In Situ Experiments. Wet latex films were cast on quartz substrates $(25.4 \mathrm{~mm} \times 25.4 \mathrm{~mm} \times 1 \mathrm{~mm})$ following the same procedure as used in the water loss measurements. When the film was dry enough to stay vertical without flowing (typically a solids content of $c a .50 \mathrm{wt} . \%$ or more), it was placed vertically in an aluminum sachet on the beamline and data acquisition started. The average solids content (by mass), obtained via gravimetry, was recorded at the start of the SANS experiment.

Ex Situ Experiments. Whereas some films were formed in situ during SANS experiments, other films were formed before being measured at the beamline. Some films on quartz slides were filmformed horizontally for three days a temperature-controlled room at $21^{\circ} \mathrm{C}$ and relative humidity of $50 \%$. Other films (film formed on quartz substrates at room temperature) were placed in an oven (name of manufacturer, model) and annealed in air at $100{ }^{\circ} \mathrm{C}$ for $3 \mathrm{~h}$ and $24 \mathrm{~h}$.

SANS Data Modelling. The fitting of the SANS profiles was performed using SasView. ${ }^{33}$ In the first drying stages, the latex particles were described using a hard sphere structure factor. The scattering length density (SLD) of the sphere was calculated according to the monomer composition $\left(0.82 \times 10^{-6} \AA^{-2}\right)$, whereas the SLD of the solvent was constrained between that of $\mathrm{H}_{2} \mathrm{O}\left(-0.56 \times 10^{-6} \AA^{-2}\right)$ and deuterated PMAA $\left(4.55 \times 10^{-6} \AA^{-2}\right)$ or deuterated SDS $\left(5.36 \times 10^{-6} \AA^{-}\right.$

${ }^{2}$ ). That is, the layer of stabilizing molecules was not modelled as a separate shell on the particles but instead as part of the surrounding medium. In the in situ experiments, as film formation progressed and the stabilizers accumulated in clusters, they were modelled by a combination of spheres and oblate spheroids for the dPMAA latex and solely as oblate spheroids for the dSDS 
latex (see Supporting information for a fitting comparison between possible models). A scheme showing the different scatterer populations included in the model is presented in Figure 1. It was found that using oblate spheroids (lentil shapes) in the model was adequate, but other shapes, such as prolate spheroids (rugby ball shape), were not adequate. The SLDs of these spherical or oblate spheroidal clusters were always set between the SLD of the polymer core and the SLD of d-PMAA or d-SDS. The scattered intensity was normalized to absolute units by dividing by the wet film thickness at each solids content, as was calculated using the gravimetry data.

\section{Stabilizer clusters}

Latex spheres

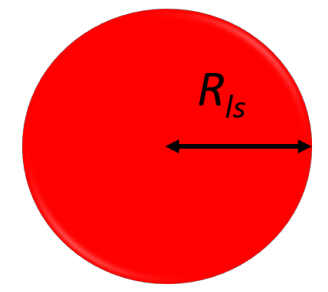

$V_{l s}, \phi_{l s}$
Hydrophilic oblate spheroids

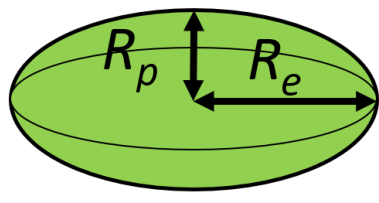

$V_{h o}, \phi_{h o}$
Hydrophilic spheres

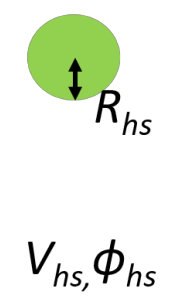

Figure 1. Scheme of the different scatterers in the SANS model: latex spheres (1s), and stabilizer clusters in the form of hydrophilic oblate spheroids (ho) (lentil shaped) and/or hydrophilic spheres (hs). Notation for their characteristic parameters is represented beside them: total volume fraction occupied by a certain population of scatterers $\left(\phi_{\mathrm{i}}\right)$, as well as radius $\left(R_{\mathrm{i}}\right)$ and volume $\left(V_{\mathrm{i}}\right)$ of a single scatterer. For the latex spheres, the stabilizer and water are treated as the surrounding phase. Both the polar $(p)$ and equatorial $(e)$ radii of the spheroids are defined.

Thereafter, the scattered intensity was modelled using the expression:

$$
I(q)=\frac{\phi_{l s}}{V_{l s}} F_{l s}^{2}(q) \cdot S_{l s}(q)+\frac{\phi_{h o}}{V_{h o}} F_{h o}^{2}(q)+\frac{\phi_{h s}}{V_{h s}} F_{h s}^{2}(q)+B
$$


where $F_{l s}, F_{h o}$, and $F_{h s}$ are the form factors of latex spheres, hydrophilic oblate spheroids, and hydrophilic spheres, respectively. Likewise, $\phi_{l s}, \phi_{h o}$, and $\phi_{h s}$ represent their corresponding volume fractions, and $V_{l s}, V_{h o}$, and $V_{h s}$ represent the volumes of the corresponding single scatterers. $S_{l s}$ is the hard sphere structure factor for the latex particles, and $B$ the background of the measurements.

The form factor of the spheres $F_{l s, h s}$ representing either the latex spheres $o r$ the hydrophilic spheres is described by the spherical Bessel function:

$$
F_{l s, h s}=3 V_{l s, h s}(\Delta \rho) \cdot \frac{\sin \left(q R_{l s, h s}\right)-q R_{l s, h s} \cos \left(q R_{l s, h s}\right)}{\left(q R_{l s}, h s\right)^{3}}
$$

$V_{l s, h s}$ is the volume of the scatterer, $R_{l s, h s}$ the radius of the sphere, and $\Delta \rho$ the difference between the scattering length density of the particle and that of the surrounding medium formed by the water and stabilizer. The hard sphere structure factor $S_{l s}$ is calculated using the Percus-Yevick approximation, which assumes the following interparticle potential to solve the Ornstein-Zernike equation:

$$
U(r)=\left\{\begin{array}{l}
\quad \infty r<2 R_{l s} \\
0 \quad r \geq 2 R_{l s}
\end{array}\right.
$$

The form factor of the hydrophilic oblate spheroids can be written as:

$$
F_{h o}=3 V_{h o}(\Delta \rho) \cdot \frac{\sin \left[q r\left(R_{p}, R_{e}, \alpha\right)\right]-q r \cos \left[\operatorname{qr}\left(R_{p}, R_{e}, \alpha\right)\right]}{\left[q r\left(R_{p}, R_{e}, \alpha\right)\right]^{3}}
$$

and

$$
r\left(R_{p}, R_{e}, \alpha\right)=\left[R_{e}^{2} \sin ^{2} \alpha+R_{p}^{2} \cos ^{2} \alpha\right]^{1 / 2}
$$

where $R_{p}$ and $R_{e}$ are the polar and equatorial radii along the rotational axis of the spheroids or perpendicular to it, respectively, and $\alpha$ is the angle between the ellipsoid axis and the vector $\vec{q}$. For randomly oriented spheroids,

$$
<F_{h o}^{2}(q)>=\int_{0}^{\pi / 2} F_{h 0}^{2}(q, \alpha) \sin \alpha d \alpha
$$




\section{RESULTS AND DISCUSSIONS}

Water loss measurements. The water loss of the two latexes upon drying was monitored to correlate the drying time with the total solids content of the samples. Figure 2a shows the solids content of the APMAA and dSDS samples as a function of time. The water contained in both latexes evaporated initially at approximately the same rate: $4.87 \times 10^{-6} \pm 0.02 \mathrm{~g} \mathrm{~cm}^{-2} \mathrm{~s}^{-1}$ for dPMAA and $4.94 \times 10^{-6} \pm 0.01 \mathrm{~g} \mathrm{~cm}^{-2} \mathrm{~s}^{-1}$ for dSDS. At this stage, the loss rate is determined by the free evaporation of water, and the measured rate is comparable to values found in the literature for pure water at similar temperatures and relative humidities: $5 \times 10^{-6} \mathrm{~g} \mathrm{~cm}^{-2} \mathrm{~s}^{-1}, 34$ and $4 \times 10^{-6} \mathrm{~g} \mathrm{~cm}^{-2} \mathrm{~s}^{-}$ ${ }^{1}{ }^{35}$ After this constant rate period, the water loss slows down after $c a .9000 \mathrm{~s}$ until the mass reaches a constant value indicating total drying. This falling rate of water loss has been correlated in the literature to the water going around or through the packed polymer particles. ${ }^{5}$ From our results, the drying of the latex stabilized with the PMAA macroRAFT agent is slowed down more significantly than the SDS-stabilized latex. It has been reported that particles with a lower glass transition temperature $\left(T_{\mathrm{g}}\right)$ show larger reductions in water loss rate because of a skin formation phenomenon. ${ }^{37}$ Therefore, one possible explanation might be based on the differences in $T_{\mathrm{g}}$ between both materials (Table 1). Experimental and theoretical studies have proven that water permeability in drying latex films scales roughly with the square of the radius of the particles, predicting a more permeable structure in the case of dPMAA. ${ }^{36}$ However, the significantly lower particle size of dSDS is expected to allow more pathways for water to evaporate. The hydrophilicity of the PMAA and its hydrogen bonding to water is likely to be greater than for SDS. These differences might explain a total drying time of $c a .9 \mathrm{~h}$ for dSDS and more than 2 days for dPMAA. Our hypothesis is that there is trapped water at particle interfaces and pockets within the 
polymer film formed by the stabilizer (d-PMAA) distribution that remains longer than those present in the dSDS latex film.

In situ monitoring of latex film formation. To understand the process of latex film formation and follow the stabilizer distribution during drying, in situ small-angle neutron scattering (SANS) experiments were carried out. In preparation, latex dispersions were cast on quartz substrates and dried partially until they were viscous enough to be placed in a vertical position. This condition corresponds to a solids content of $58 \mathrm{wt} . \%$ for dPMAA and $49 \mathrm{wt} . \%$ for dSDS, as indicated in the inset of Figure 2a by red and black arrows, respectively. The lower solids content of the SDS latex to fulfill this condition can be attributed to the higher resistance to flow (i.e. viscosity) that this dispersion presents, possibly related to the lower particle size of this latex. The partially dried films were positioned in an aluminum sachet and placed in the beamline for SANS data acquisition (Figure 2b). 


\section{(a)}

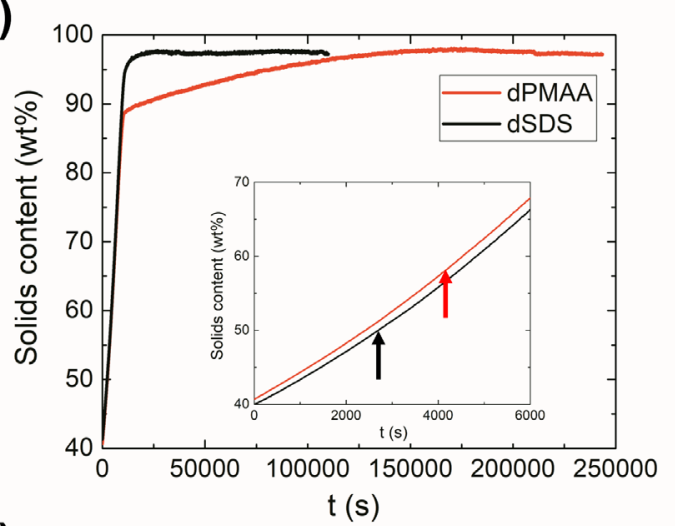

(b) $\mathrm{t}$ (s)

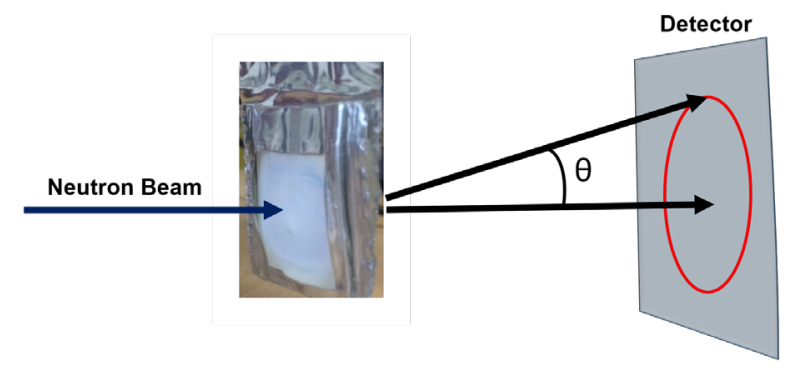

Figure 2. (a) Water loss measurements: solids content as a function of time for the dPMAA and dSDS latexes when drying in a temperature-controlled room at $21^{\circ} \mathrm{C}$. The inset shows the times when samples were placed in the beamline, indicated by the red (dPMAA) and black (dSDS) arrows. (b) SANS setup to follow in situ the latex film formation. The wet latex film is placed vertically in an aluminum sachet and the neutron beam transmits through it to reach the detector.

SANS profiles of the initial bulk dispersions (before casting, empty black symbols) and the partially dried films with increasing solids contents are presented in Figure 3. Best fits are also presented as the solid lines, and all the relevant modelling parameters for the two latexes can be found in Table 2 and Error! Reference source not found.. The initial bulk dispersion, at 40 wt.\%, of the latex stabilized with d-PMAA macroRAFT agent (dPMAA) shows clear features of spherical scatterers whose size correlates well with that of the latex particles (Figure 3a and Table 1). The SANS profile was successfully fitted by a hard sphere model which - instead of including 
a shell - considers a surrounding medium that is composed of the deuterated PMAA stabilizer and water. As drying proceeds, the main peak located at $c a .4 \times 10^{-3} \AA^{-1}$ becomes narrower as a result of the decreased particle spacing and particle packing, while the particle volume fraction increases in this "wet state". When the solids content reaches 68 wt.\% (approximately equal to 76 vol.\%, which is only slightly above 74 vol.\%, where mono-sized spheres are the most dense-packed), two processes start to develop in parallel. In one process, packed latex particles deform to fill the empty spaces between them. This process is driven by surface tension and capillary forces. ${ }^{38}$ As a result, the peaks in the SANS profile shift to a lower $q$, and the average particle size and polydispersity increase as the shape is distorted from a sphere to create a dimension larger than the initial diameter. The onset of diffusion of polymer chains across particle boundaries leading to particle coalescence is reached. When some particles coalesce and lose their initial spherical shape, the volume fraction of the remaining spherical particles decreases. (This is why $\phi_{l s}$ initially increases during drying but then decreases for both latex types.)

In the second process, the stabilizers re-arrange themselves. The rise in intensity at low $q$ indicates the appearance of a new population of larger-scale scatterers, which we model as deuterated stabilizer aggregates in the shape of oblate spheroids (disc-like or lentil shaped). These clusters presented SLDs in between that of the polymer core of the latex particles and the SLD of deuterated PMAA. This fact indicates that they are not only composed of the PMAA stabilizer, but still contain water. It was not possible to obtain adequate fits to the data using a model with spherical aggregates. As film formation continues and the solids content increases, these aggregates increase in dimensions up to $100 \mathrm{~nm} \times 280 \mathrm{~nm}$ at a solids content of $78 \mathrm{wt} . \%$ and retain this size until the end of the in situ experiment. From a solids content of 73 wt.\% and above, a second type of stabilizer aggregate, in the form of polydisperse spheres of $9.5 \mathrm{~nm}$ in radius, appears and retains 
its shape and size until the end of the in situ experiment. This radius is about the length of the PMAA block in the stabilizer, which is composed of 30 MAA units of approximately two times the length of a C-C bond $(0.154 \mathrm{~nm}): 2 \times 0.154 \times 30=9.2 \mathrm{~nm}$. (A geometric model will be presented in a later section.)

(a)
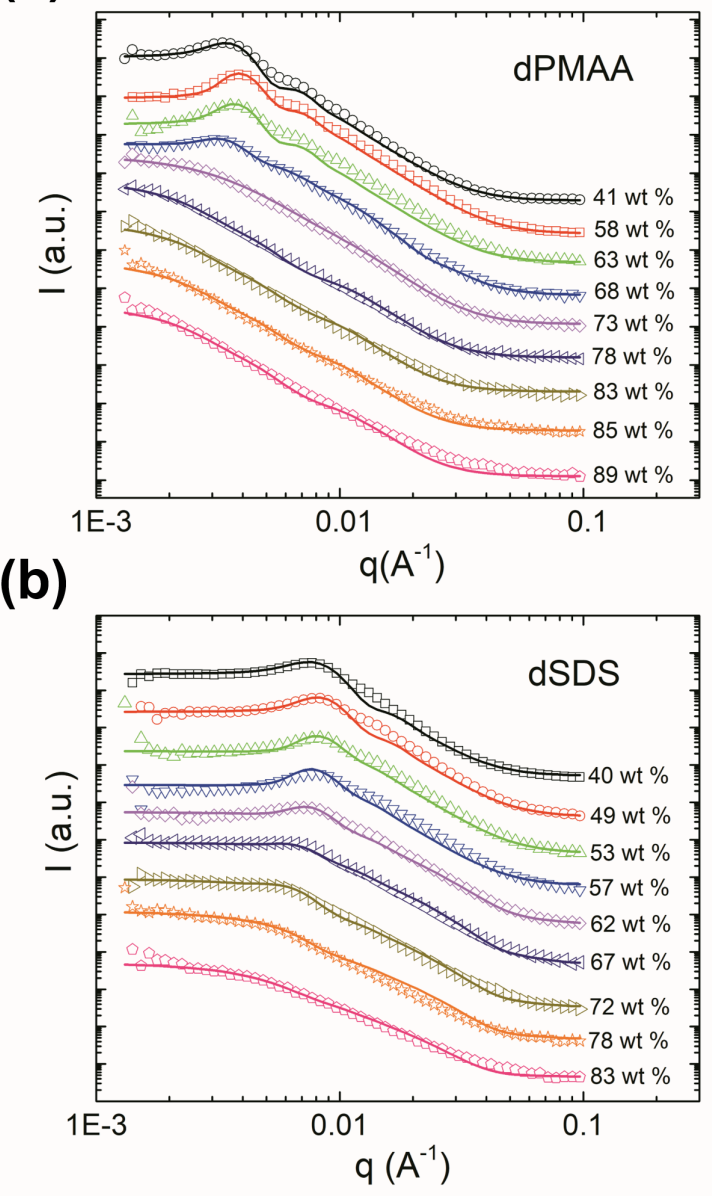

Figure 3. SANS profiles of latex dispersions acquired in situ as they dry at different solids contents: particles stabilized with (a) d-PMAA macroRAFT agent (dPMAA) and (b) d-SDS (dSDS). Solid lines represent best fits to experimental data using the parameters presented in Table 1 and Table 2 . The intensity axis has been shifted by an arbitrary scale factor. 
Table 2. Modelling parameters for SANS profiles of dPMAA at different solids content during film formation: model used, volume fraction of latex spheres $\left(\phi_{\mathrm{ls}}\right)$, scattering length densities of their core $\left(b_{c}^{l_{s}}\right)$ and solvent $\left(b_{s}^{l_{s}}\right)$, radius of latex spheres $\left(R_{\mathrm{ls}}\right)$ and polydispersity (PDI), volume fraction of hydrophilic oblate spheroids $\left(\phi_{\text {ho }}\right)$, scattering length densities of their core $\left(b^{\text {ho }}{ }_{c}\right)$ and surroundings $\left(b_{s}^{h o}\right)$, polar and equatorial radii of oblate spheroids $\left(R_{\mathrm{p}}\right.$ and $\left.R_{\mathrm{e}}\right)$, volume fraction and radius of hydrophilic spheres $\left(\phi_{\mathrm{hs}}\right.$ and $\left.R_{\mathrm{hs}}\right)$, scattering length densities of their core $\left(b^{h o} c\right)$ and their surroundings $\left(b^{h o} s\right)$, and total volume fraction of hydrophilic species $\left(\phi_{\mathrm{ht}}\right)$.

\begin{tabular}{|c|c|c|c|c|c|c|c|c|c|c|c|c|c|c|c|}
\hline $\begin{array}{l}\text { wt. } \\
\%^{a}\end{array}$ & Model $^{\text {b }}$ & $\phi_{\text {Is }}$ & $\begin{array}{c}b^{l s}{ }_{c} \\
\left(10^{-}\right. \\
\left.6 / \AA^{2}\right)\end{array}$ & $\begin{array}{c}b^{\text {ls }} \\
\left(10^{-6} / \AA^{2}\right)\end{array}$ & $\begin{array}{c}R_{\mathrm{Is}}(\mathrm{nm}) \\
\quad / \mathrm{PDI}\end{array}$ & $\phi_{\text {ho }}$ & $\begin{array}{l}\mathbf{b}^{\text {ho }}{ } \\
\left(10^{-}\right. \\
\left.\sigma / \AA^{2}\right)\end{array}$ & $\begin{array}{l}\mathbf{b}^{\text {ho }}{ }_{s} \\
\left(10^{-}\right. \\
\left.6 / \AA^{2}\right)\end{array}$ & $\begin{array}{c}R_{\mathrm{p}} \\
(\mathbf{n m}) \\
/ \mathbf{P D I}\end{array}$ & $\begin{array}{c}R_{\mathrm{e}} \\
(\mathbf{n m}) \\
/ \mathbf{P D I}\end{array}$ & $\phi_{\mathrm{hs}}$ & $\begin{array}{l}\mathbf{b}^{\mathrm{hs}}{ }_{\mathrm{c}} \\
\left(10^{-}\right. \\
\left.6 / \AA^{2}\right)\end{array}$ & $\begin{array}{l}\mathbf{b}^{\mathrm{hs}}{ }_{\mathrm{s}} \\
\left(10^{-}\right. \\
\left.6 / \AA^{2}\right)\end{array}$ & $\begin{array}{c}\boldsymbol{R}_{\mathrm{hs}}(\mathrm{nm}) \\
\quad / \mathrm{PDI}\end{array}$ & $\phi_{\mathrm{ht}} \mathrm{c}^{\mathrm{s}}$ \\
\hline 41 & 1s & 0.44 & 0.8 & 2.46 & $89 / 0.1$ & - & - & - & - & - & - & - & - & - & - \\
\hline 63 & 1s & 0.52 & 0.8 & 2.7 & $89 / 0.1$ & - & - & - & - & - & - & - & - & - & - \\
\hline 68 & ls + ho & 0.45 & 0.8 & 2.7 & $94 / 0.12$ & 0.019 & 4 & 1 & $17 / 0$ & $55 / 0$ & - & - & - & - & 0.019 \\
\hline 83 & ho + hs & - & - & - & - & 0.003 & 4.5 & 0.8 & $50 / 0$ & $140 / 0$ & 0.001 & 4.5 & 0.8 & $9.5 / 1$ & 0.004 \\
\hline 85 & ho + hs & - & - & - & - & 0.004 & 4.5 & 0.8 & $50 / 0$ & 140 / 0 & 0.001 & 4.5 & 0.8 & $9.5 / 1$ & 0.005 \\
\hline 89 & ho + hs & - & - & - & - & 0.006 & 4.5 & 0.8 & $50 / 0$ & $140 / 0$ & 0.002 & 4.5 & 0.8 & $9.5 / 1$ & 0.008 \\
\hline $100^{\mathrm{d}}$ & ho + hs & - & - & - & - & 0.005 & 4.5 & 0.8 & $42 / 0$ & $140 / 0$ & 0.008 & 4.5 & 0.8 & $5.5 / 0.9$ & 0.012 \\
\hline
\end{tabular}

${ }^{\mathrm{a} S}$ Solids content as determined by gravimetry. ${ }^{\mathrm{b}} \mathrm{ls}=$ Latex (hard) spheres, ho $=$ Hydrophilic oblate spheroids, and hs $=$ Hydrophilic spheres. ${ }^{\mathrm{c}} \phi_{\mathrm{ht}}=$ $\phi_{\mathrm{ho}}+\phi_{\mathrm{hs} .}{ }^{\mathrm{d}}$ Dried for 3 days at room temperature. ${ }^{\mathrm{e}}$ Annealed at $100{ }^{\circ} \mathrm{C}$ for $1 \mathrm{~h} .{ }^{\mathrm{f}}$ Annealed at $100{ }^{\circ} \mathrm{C}$ for $3 \mathrm{~h} .{ }^{\mathrm{g}}$ Annealed at $100{ }^{\circ} \mathrm{C}$ for $24 \mathrm{~h}$. 
SANS profiles for the latex dispersion stabilized with d-SDS (dSDS) are presented in Figure $3 b$. Similarly, the profile of the initial dispersion can be fitted by a model of hard spheres surrounded by a medium that is composed of the deuterated SDS stabilizer and water. The onset of particle deformation, indicated by the shift to lower $q$ of the SANS peaks, takes place earlier than for the d-PMAA-stabilized latex (around $53 \mathrm{wt} . \%$ ). This fact correlates with the faster drying observed for dSDS in the water loss measurements (Figure 2). However, the particle identity in some regions is retained for longer (up to $83 \mathrm{wt} . \%$ ), which is a possible consequence of a higher polymer glass transition temperature when compared with dPMAA (Table 1). A contribution arising at low $q$ is detected from 62 wt. $\%$ onwards and associated with oblate spheroidal clusters of deuterated SDS. These clusters presented SLDs in between that of the polymer core of the latex particles and the SLD of deuterated SDS. The data cannot be described adequately by spherical clusters. The size of the oblate spheroids increases up to $15 \mathrm{~nm} \times 118 \mathrm{~nm}$ at a solids content of $83 \mathrm{wt} . \%$. These dimensions are well over an order of magnitude greater than the dimensions of SDS molecules, which have a tail length of $1.67 \mathrm{~nm} .^{39}$ 
Table 3. Modelling parameters for SANS profiles of dSDS at different solids content during film formation: model used, volume fraction of latex spheres $\left(\phi_{\mathrm{ls}}\right)$, scattering length densities of their core $\left(b_{c}^{l_{s}}\right)$ and solvent $\left(b^{l_{s}}\right)$, radius of latex spheres $\left(R_{\mathrm{ls}}\right)$ and polydispersity (PDI), volume fraction of oblate spheroids $\left(\phi_{\mathrm{ho}}\right)$, scattering length densities of their core $\left(b_{c}^{\text {ho }}\right)$ and surroundings $\left(b^{h o}\right)$, polar and equatorial radii of oblate spheroids $\left(R_{\mathrm{p}}\right.$ and $\left.R_{\mathrm{e}}\right)$, and total volume fraction of hydrophilic species $\left(\phi_{\mathrm{ht}}\right)$.

\begin{tabular}{|c|c|c|c|c|c|c|c|c|c|c|c|}
\hline $\begin{array}{l}\text { wt. } \\
\%^{\mathbf{a}}\end{array}$ & Model $^{\text {b }}$ & $\phi_{\text {ls }}$ & $\begin{array}{c}b^{l s}{ }_{c} \\
\left(10^{-6} / \AA^{2}\right)\end{array}$ & $\begin{array}{c}b^{L_{S}} \\
\left(10^{-6} / \AA^{2}\right)\end{array}$ & $\underset{(\mathrm{nm}) / \mathrm{PDI}}{R_{\mathrm{Is}}}$ & $\phi$ ho & $\begin{array}{c}b^{h o}{ }_{c} \\
\left(10^{-6} / \AA^{2}\right)\end{array}$ & $\begin{array}{c}b^{h o}{ }_{s} \\
\left(10^{-6} / \AA^{2}\right)\end{array}$ & $R_{\mathrm{p}}(\mathrm{nm}) / \mathrm{PDI}$ & $R_{\mathrm{e}}(\mathrm{nm}) / \mathrm{PDI}$ & $\phi_{\mathrm{ht}^{\mathrm{c}}}$ \\
\hline 40 & 1s & 0.39 & 0.8 & 2.5 & $35 / 0.15$ & - & - & - & - & - & - \\
\hline 49 & ls & 0.46 & 0.8 & 2.5 & $36 / 0.15$ & - & - & - & - & - & - \\
\hline 53 & ls & 0.53 & 0.8 & 2.5 & $40 / 0.15$ & - & - & - & - & - & - \\
\hline 62 & ls + ho & 0.5 & 0.8 & 2.5 & $42 / 0.15$ & 0.007 & 5.36 & 0.56 & $7 / 0$ & $30 / 0$ & 0.007 \\
\hline 67 & ls + ho & 0.4 & 0.8 & 2.5 & $46 / 0.15$ & 0.011 & 5.36 & 0.56 & $8 / 0$ & $30 / 0$ & 0.011 \\
\hline 72 & ls + ho & 0.35 & 0.8 & 2.5 & $44 / 0.15$ & 0.007 & 5.36 & 0.56 & $8 / 0$ & $50 / 0$ & 0.007 \\
\hline 78 & ls + ho & 0.2 & 0.8 & 2.5 & $44 / 0.15$ & 0.010 & 5.36 & 0.56 & $8 / 0$ & $59 / 0$ & 0.010 \\
\hline $100^{c}$ & ho & - & - & - & - & 0.012 & 4.5 & 0.8 & $15 / 0.4$ & $123 / 0$ & 0.012 \\
\hline $100^{\mathrm{d}}$ & ho & - & - & - & - & 0.002 & 4.5 & 0.8 & $25 / 0.4$ & $170 / 0$ & 0.002 \\
\hline $100^{\mathrm{e}}$ & ho & - & - & - & - & 0.002 & 4.5 & 0.8 & $25 / 0.4$ & $170 / 0$ & 0.002 \\
\hline $100^{\mathrm{f}}$ & ho & - & - & - & - & 0.001 & 4.5 & 0.8 & $20 / 0.4$ & $80 / 0$ & 0.001 \\
\hline
\end{tabular}

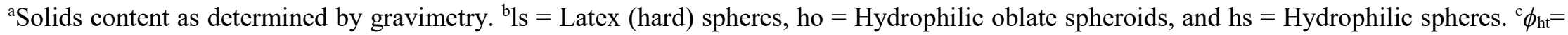
$\phi_{\text {he. }}{ }^{\mathrm{d}}$ Dried for 3 days at room temperature. ${ }^{\mathrm{e}}$ Annealed at $100{ }^{\circ} \mathrm{C}$ for $1 \mathrm{~h}$. ${ }^{\mathrm{f}}$ Annealed at $100{ }^{\circ} \mathrm{C}$ for $3 \mathrm{~h} .{ }^{\mathrm{g}}$ Annealed at $100{ }^{\circ} \mathrm{C}$ for $24 \mathrm{~h}$ 
Structures of films prepared ex-situ. To shed light on the film structure evolution after complete drying, a second round of SANS experiments was carried out on films aged ex situ at room temperature or at a temperature of $100{ }^{\circ} \mathrm{C}$. The elevated temperature was chosen to accelerate the rate of any phase restructuring. The corresponding SANS profiles and best fits to the data are presented in Figure 4. The last profile from the in situ experiment has been included in the figure for comparison.

In dPMAA (Figure 4a, Table 2), after three days of film formation, the stabilizer remains in the form of ellipsoidal aggregates of the same size as at the end of the in situ experiment, but the spheres shrink down from $9.5 \mathrm{~nm}$ to $5.5 \mathrm{~nm}$ in radius. The glass transition of the PMAA macroRAFT has been measured to be $c a .140{ }^{\circ} \mathrm{C}$ (see Supporting Information). Although the PMAA stabilizing layer will remain glassy, even at the annealing temperature of $100{ }^{\circ} \mathrm{C}$, it is still expected to be flexible. In other work, ${ }^{40}$ core-shell particles with a glassy shell were deformable as a result of their viscous core and able to undergo film formation. During the drying stage, the hydrophilic PMAA chains will be plasticized by water.

In contrast, the stabilizer distribution in the film cast from dSDS latex particles is less stable over time. After three days of drying, the surfactant aggregates have doubled their size when compared to the end of the in situ experiment, to reach dimensions of $15 \mathrm{~nm} \times 123 \mathrm{~nm}$. Upon annealing at $100{ }^{\circ} \mathrm{C}$ they grow to $25 \mathrm{~nm} \times 170 \mathrm{~nm}$ for annealing times of $1 \mathrm{~h}$ and $3 \mathrm{~h}$, and then finally shrink to $20 \mathrm{~nm} \times 80 \mathrm{~nm}$ (while increasing in number) when annealed for $24 \mathrm{~h}$ (Table 3). 

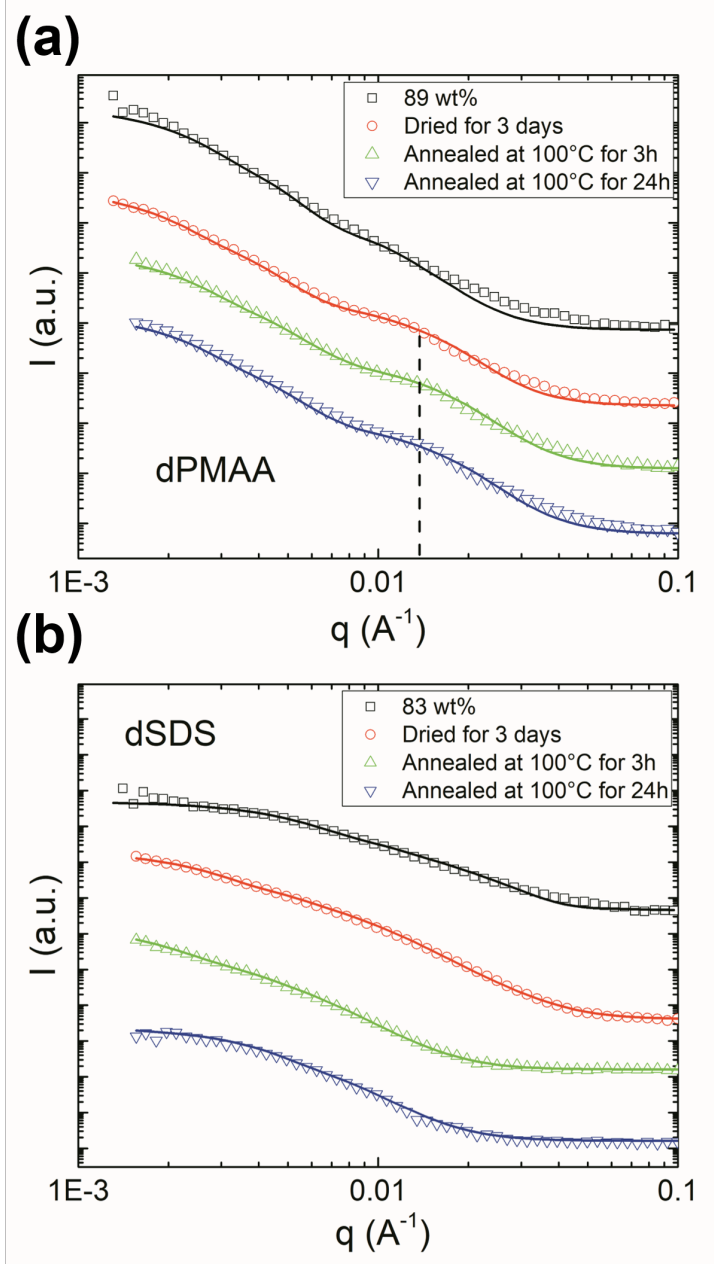

Figure 4. SANS profiles from ex situ experiments on dried and annealed films made of latex particles stabilized with (a) d-PMAA macroRAFT (dPMAA) and (b) d-SDS (dSDS). Solid lines represent best fits to experimental data using the parameters presented in Tables 2 and 3. The dashed vertical line indicates the position of a broad peak that arises from scatters with a diameter that varies from 9.5 to $5.5 \mathrm{~nm}$.

Film formation model and interfacial free energy considerations. A scheme showing the evolution of the distribution of hydrophilic species in the film during drying and after annealing is presented in Figure 5. It is worth to recall here that for dPMAA, the stability of the latex particles is ensured by the in situ formation of d-PMAA- $b-\mathrm{P}(\mathrm{BA}-\mathrm{co}-\mathrm{MMA})$ amphiphilic block copolymers resulting 
from chain extension of the d-PMAA macroRAFT block. As drying proceeds, these amphiphilic block copolymers first form oblate spheroidal clusters, with d-PMAA segments in the core, that are likely to be located at the boundaries between particles (Figure 5b). As the particles deform to fill space, they will assume a polyhedral shape with flat faces at the points of contact between neighboring spheres. Face-centered cubic-packed particles have 12 nearest neighbors and create rhombic dodecahedra upon their deformation. Figure 6 depicts an idealized geometrical model of the location of ellipsoidal stabilizer clusters along the faces of neighboring dodecahedra.

The short face diagonal in a rhombic dodecahedron is $2 / \sqrt{3} L$, where $L$ is the edge length. ${ }^{41}$ To a first approximation, the equatorial radius of an oblate spheroid, $R_{\mathrm{e}}$, at the boundary between dodecahedral faces will be one-half of this distance, which is $1 / \sqrt{3} L$. The radius of the originally spherical latex particle, $R$, can be estimated to be equal to one-half of the long face diagonal, i.e. $R=1 / 2 \cdot 2 \sqrt{2} / \sqrt{3} L=\sqrt{2} / \sqrt{3} L$. That makes the equatorial radius of the oblate spheroid related to the particle radius as $R_{e}=R / \sqrt{2}$. At a solids content of $68 \mathrm{wt} . \%$, the radius of the dPMAA particles is $94 \mathrm{~nm}$. At this stage, our SANS analysis found $R_{\mathrm{e}}$ to be $55 \mathrm{~nm}$, which is quite close to the value of $66 \mathrm{~nm}(=94 / \sqrt{2})$ that is predicted with our simple geometrical model. Therefore, it seems reasonable to say that the oblate spheroids are at the common face of two adjacent cells, with some overhang. The formation of these oblate spheroids might be related to the heterogeneous closure of interstices reported in particles smaller than $90 \mathrm{~nm}$, where the closing of some interstices leads to the enlarging of the remaining ones. ${ }^{42}$ These enlarged interstices can then become a reservoir for hydrophilic species. At 73 wt.\% solids, the oblate spheroids grow, while there is the emergence of spheres, which we interpret as spherical aggregates of d-PMAA- $b$-P(BA-co-MMA) macroRAFT agent, i.e. micelles with d-PMAA segments in the core (Figure 5c). These spheres have a radius of $9.5 \mathrm{~nm}$ according to SANS, which is very close to the maximum expected radius 
determined by considering the length an extended d-PMAA chain of $2600 \mathrm{~g} \mathrm{~mol}^{-1}$ (30 repeating units leading to $c a .9 .2 \mathrm{~nm}$ total length), possibly indicating the presence of remaining water within them. In the next drying stage (78-89 wt.\%, Figure 5 d) neighboring oblate spheroids merge, while the size and shape of spherical micelles remain unaffected. When the film is fully dried or annealed, hydrophilic spheres reduce considerably in size, as a consequence of the water loss from inside the micelles and the further coalescence and void closure. We expect some interfacial broadening at the boundary between the PMAA micelles and the surrounding film, which can explain why the radius is slightly larger than the extended chain PMAA chain length.

Whereas the deuterated PMAA chains form a stabilizing layer on the original latex particles, these chains do not remain in continuous layers around the particles during film formation. In a "classic" study of film formation of latex particles with poly(acrylic acid) (PAA) enriched shells ${ }^{43}$ SANS and electron microscopy revealed that the PAA created the walls in a cellular "honeycomb" structure in the film. A PAA honeycomb structure (in the acid form) was stable during film formation and after annealing films up to temperatures of $110{ }^{\circ} \mathrm{C}$. At a temperature of $140{ }^{\circ} \mathrm{C}$, however, when the core and PAA molecular mobility is greater, the PAA honeycomb structure broke up. Fragments of the shells were expelled and formed clusters, much like what we see in the present study. Whereas, the PAA constituted $5 \mathrm{wt} . \%$ in their system, the PMAA in our latex is present at only 1 wt.\%. This difference in the expected thickness of stabilizing layers could explain why there is no indication of a continuous PMAA honeycomb structure during film formation in our experiments. Two other possible contributions to the breakup of the honeycomb structure are the polydispersity of the particles and the deformation that the particle cores undergo, which can fracture the PMAA stabilizing layer. 
In the experiments of Joanicot et al., PAA-enriched boundaries between particles in films were rehydrated with $\mathrm{D}_{2} \mathrm{O}$ to enable their analysis by SANS. The fact that scattering from the $\mathrm{D}_{2} \mathrm{O}-$ highlighted honeycomb structure was possible indicates that PAA prevent particle coalescence and the structures were not fragmented. We immersed dried films of the PMAA-stabilized and SDSstabilized latexes in $\mathrm{D}_{2} \mathrm{O}$ for prolonged times. However, we were not able to see characteristic Bragg scattering from a cellular structure in SANS experiments. This result is an indirect indication that the PMAA stabilizer layers were fragmented and present only in the ellipsoidal clusters.

We next consider reasons for the changes in the stabilizer structures over time. Our data indicate that the evolution of surfactant distributions in latex films is driven by a reduction in the interfacial free energy, which can be monitored by following the surface area-to-volume ratio $(A / V) .{ }^{13} \mathrm{We}$ assume that there is a constant interfacial energy, $\gamma$, between the stabilizer and the polymer phases. A change in the interfacial area, $\Delta A$, will lead to a change in the interfacial free energy, $\Delta F=\gamma \Delta A$. It is expected that $A / V$ will tend to reduce its value to minimize the interfacial free energy, $F$, and evolve towards a more thermodynamically favored system state. ${ }^{44}$ The structural rearrangement is opposed by the viscosity of the polymer, as flow requires energy dissipation.

For each sample, we calculated $A / V$ from the measurement of the dimensions of the oblate spheroids or spheres and their number per unit volume. However, Figure 7 shows that the $A / V$ for dPMAA stays fairly constant throughout the in situ experiment. This counter-intuitive result can be explained by considering the reduced mobility of the PMAA chains, which are covalently bonded to P(BA-co-MMA) segments in the core of the particles. Although the hydrophilic oblate spheroids become larger in time by swelling and merging with neighboring oblate spheroids, thus reducing the surface area-to-volume ratio, the appearance of hydrophilic spheres compensates this 
effect with their high surface area. The hydrophilic material contained in these spheres is spatially confined due to the geometry of the interstices and the bonding to core polymer chains. When the film is fully dried or annealed, a significant increase in $A / V$ is observed because of the reduction in the radius of the hydrophilic spherical clusters, which do not have enough mobility to migrate and are pushed together by further coalescence.

(a)

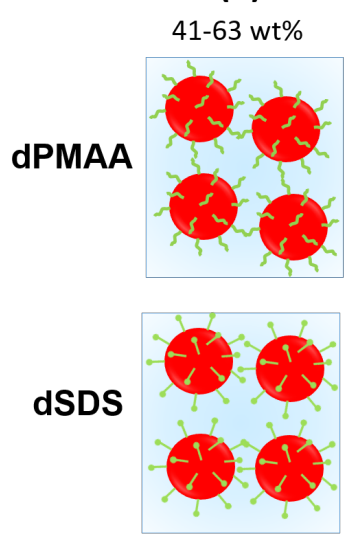

40-57 wt\% (b)
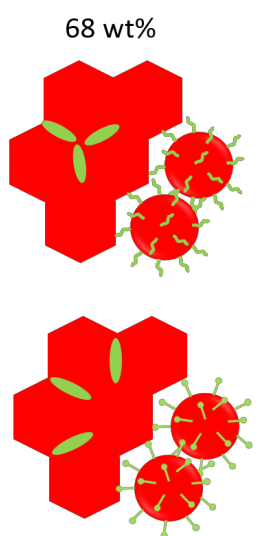

62-78 wt\% (c)

$73 \mathrm{wt} \%$
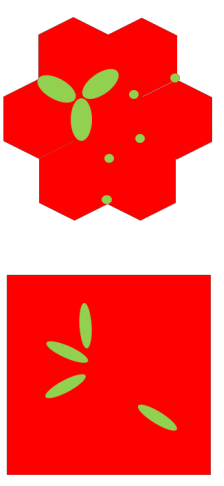

$83 w t \%$ (d) 78-89 wt\%
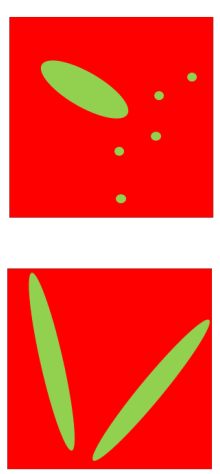

$100 \mathrm{wt} \%$ (e)

$100 \mathrm{wt} \%$ or annealed at $100^{\circ} \mathrm{C}$ for $24 \mathrm{~h}$
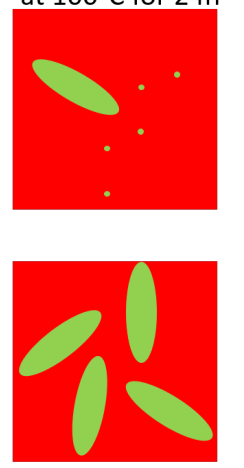

Annealed at $100^{\circ} \mathrm{C}$ for $24 \mathrm{~h}$

Figure 5. Film formation model for dPMAA (upper row) and dSDS (lower row) at different solids content during drying and after annealing. The green shapes represent clusters of hydrophilic species within the drying or annealed film. 


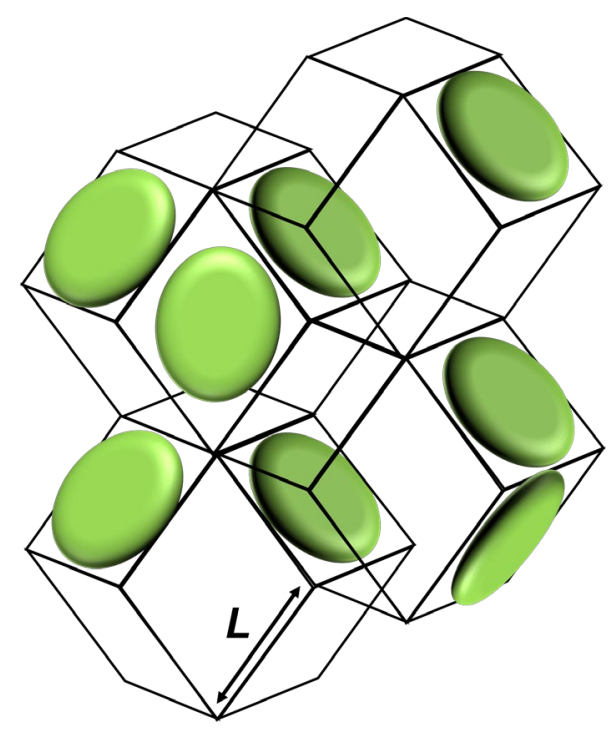

Figure 6. Geometric model of packed latex particles deformed into rhombic dodecahedra, with oblate spheroidal clusters of stabilizers resting on the faces of the polyhedra. The edge of the face has a length of $L$, as labelled. 


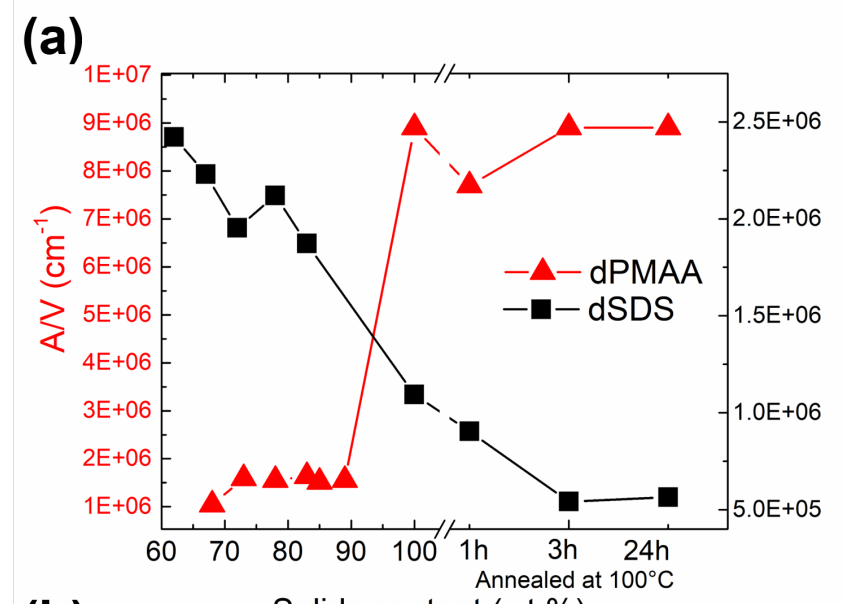

(b)

Solids content (wt.\%)

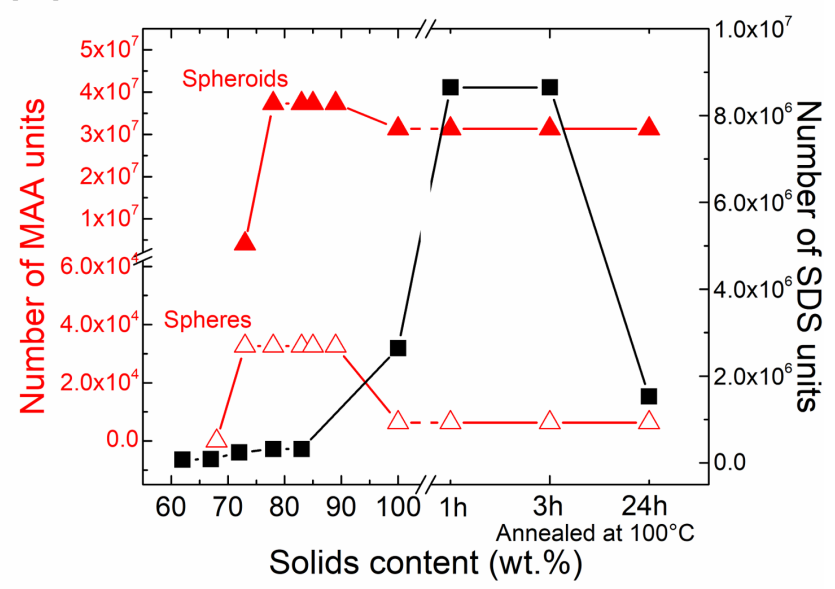

Figure 7. (a) Surface area-to-volume (A/V) ratio of hydrophilic clusters in films of d-SDSstabilized (left axis) and d-PMAA-stabilized (right axis) latexes as a function of their solids content (and annealing time). (b) Number of MAA units in one oblate spheroid (filled triangle, left axis) or one sphere (empty triangle, left axis) and number of SDS units (filled squares, right axis) as a function of solids content (and annealing time).

Next, we consider the surfactant system. Our film formation model proposed for the latex stabilized with SDS can be seen in Figure 5 (lower row). In films with a solids content of 62 wt.\% and higher, ellipsoidal clusters can be detected, which we presume to be formed at the polymer particle boundaries. The dimensions of the ellipsoid are much greater than individual SDS molecules, which indicates that the oblate spheroids are clusters of surfactant and not cylindrical 
micelles. The oblate spheroids grow in size and they eventually merge together near the end of the in situ experiment (Figure 5d). Upon annealing, the structure is affected, and the clusters appear to split into oblate spheroids (Figure 5e). Furthermore, Joanicot et al.$^{43}$ found that SDS surfactant monolayers on particles were not able to prevent particle coalescence. The surfactant layers fragmented during film formation and never created a honeycomb structure, which is in full agreement with our results.

Figure 7 shows that the surface area-to-volume ratio decreases as the drying and film formation proceeds, and finally reaches a plateau after $3 \mathrm{~h}$ of annealing at $100{ }^{\circ} \mathrm{C}$. Hence, there is evidence that the structural changes are being driven by the reduction of the interfacial free energy. In contrast to the PMAA stabilizer, the SDS can move independently from the polymer phase to find the structures that are thermodynamically favorable. Using a value for the molecular volume of an SDS unit of $0.35 \mathrm{~nm}^{3},{ }^{39}$ and calculating that of MAA from its molar volume $\left(67 \mathrm{~cm}^{3} / \mathrm{mol}\right)$ to be $0.11 \mathrm{~nm}^{3}$, it is possible to plot the number of stabilizer units per hydrophilic cluster as a function of the solids content and annealing time (Figure 7b). The graph shows how the number of SDS units per cluster evolves in a steadier manner than the number of MAA units, which show two main plateaus without a transition in between. This observation supports our interpretation of the variations in MAA distribution as a change in configuration, in contrast with the migration of SDS units to minimize interfacial energy.

\section{CONCLUSIONS}

We have performed both in situ and ex situ SANS experiments to follow the film formation of two types of latex particles, which differ in their stabilizer: either a covalently bonded macroRAFT agent (based on deuterated PMAA) or a physically adsorbed surfactant (using deuterated SDS). 
By fitting the SANS data and combining with gravimetry experiments, we have ascertained the hydrophilic species distribution within the films and followed its evolution over drying time.

For the latex film stabilized with d-SDS, the surfactant restructures into oblate spheroidal clusters, present at the common faces between adjacent particles, which increase in size and then merge as drying progresses, reaching equatorial and polar radii of up to $170 \mathrm{~nm}$ and $25 \mathrm{~nm}$, respectively. This process decreases the surface area-to-volume ratio of the surfactant phase, driven by a reduction in the interfacial free energy. Annealing of these films results in a breakup of the oblate spheroids into smaller oblate spheroids of $20 \mathrm{~nm}$ in polar radius and $80 \mathrm{~nm}$ in equatorial radius.

For the latex synthesized in the presence of d-PMAA-based macroRAFT agent, the stabilizer initially arranges in oblate spheroidal clusters, which are most likely present at the common face between two adjacent particles. With additional drying, the spheroids start increasing in size, and a population of hydrophilic spheres (radius of $9.5 \mathrm{~nm}$ ) appears, which are interpreted as PMAA micelles. This process does not result in a decrease in the interfacial free energy, as the stabilizer is covalently bonded to the particle core and cannot migrate to other areas, but to a change in configuration. When fully dried, the hydrophilic spheres are reduced significantly in size (to a radius of $5.5 \mathrm{~nm}$ ). The structure of these films is unaffected by annealing at $100{ }^{\circ} \mathrm{C}$ for up to $24 \mathrm{~h}$.

The results presented here shed light on the distribution of hydrophilic species in latex films at the nanoscale, which has previously been insufficiently explored. Our work provides valuable insights into the influence of the stabilizer mobility on the final structure of latex films and, by extension, on their properties.

\section{SUPPORTING INFORMATION}


Measurement of monomer conversion. Comparison of SANS fittings obtained with different model geometries. Zoomed in SANS profiles. Differential scanning calorimetry (DSC) of the dPMAA macroRAFT agent. Atomic force microscopy of the top surface of the dried latex coatings.

\section{AUTHOR INFORMATION}

\section{Corresponding Author}

*i.martin-fabiani@lboro.ac.uk

\section{ACKNOWLEDGMENTS}

This work was funded by the European Union Seventh Framework Programme BARRIER-PLUS project (FP7-SME-2012-2, No. 304758). We benefitted from discussions with Dr Richard Heenan (ISIS Neutron and Muon Source). We thank Violeta Doukova (University of Surrey) for general laboratory assistance, and Manel Taam (C2P2) for performing DSC analyses.

\section{REFERENCES}

(1) Keddie, J. L.; Routh, A. Fundamentals of Latex Film Formation: Processes and Properties; Springer, 2010.

(2) Keddie, J. L. Film Formation of Latex. Mater. Sci. Eng. R Reports. 1997, 21, 101-170.

(3) Zhao, C.-L.; Holl, Y.; Pith, T.; Lambla, M. Surface Analysis and Adhesion Properties of Coalesced Latex Films. Br. Polym. J. 1989, 21, 155-160.

(4) Shirakbari, N.; Ebrahimi, M.; Salehi-Mobarakeh, H.; Khorasani, M. Effect of Surfactant Type and Concentration on Surfactant Migration, Surface Tension, and Adhesion of Latex Films. J. Macromol. Sci. Part B. 2014, 53, 1286-1292.

(5) Charmeau, J. Y.; Kientz, E.; Holl, Y. Adhesion of Latex Films; Influence of Surfactants. 
Prog. Org. Coatings. 1996, 27, 87-93.

(6) Agarwal, N.; Farris, R. J. Water Absorption by Acrylic-Based Latex Blend Films and Its Effect on Their Properties. J. Appl. Polym. Sci. 1998, 1407-1419.

(7) Liu, Y.; Soer, W.-J.; Scheerder, J.; Satgurunathan, G.; Keddie, J. L. Water Vapor Sorption and Diffusion in Secondary Dispersion Barrier Coatings: A Critical Comparison with Emulsion Polymers. ACS Appl. Mater. Interfaces. 2015, 7, 12147-12157.

(8) Lee, W. P.; Gundabala, V. R.; Akpa, B. S.; Johns, M. L.; Jeynes, C.; Routh, A. F. Distribution of Surfactants in Latex Films: A Rutherford Backscattering Study. Langmuir. 2006, 22, 5314-5320.

(9) Baesch, S.; Siebel, D.; Schmidt-Hansberg, B.; Eichholz, C.; Gerst, M.; Scharfer, P.; Schabel, W. Comparison of Surfactant Distributions in Pressure-Sensitive Adhesive Films Dried from Dispersion under Lab-Scale and Industrial Drying Conditions. ACS Appl. Mater. Interfaces. 2016, 8, 8118-8128.

(10) Arnold, C.; Thalmann, F.; Marques, C.; Marie, P.; Holl, Y. Surfactant Distribution in Waterborne Acrylic Films. 1. Bulk Investigation. J. Phys. Chem. B 2010, 114, 9135-9147.

(11) Zhao, C. L.; Holl, Y.; Pith, T.; Lambla, M. FTIR-ATR Spectroscopic Determination of the Distribution of Surfactants in Latex Films. Colloid Polym. Sci. 1987, 265, 823-829.

(12) Belaroui, F.; Hirn, M. P.; Grohens, Y.; Marie, P.; Holl, Y. Distribution of Water-Soluble and Surface-Active Low-Molecular-Weight Species in Acrylic Latex Films. J. Colloid Interface Sci. 2003, 261, 336-348.

(13) Tzitzinou, A.; Jenneson, P. M.; Clough, A. S.; Keddie, J. L.; Lu, J. R.; Zhdan, P.; Treacher, K. E.; Satguru, R. Surfactant Concentration and Morphology at the Surfaces of Acrylic Latex Films. Prog. Org. Coatings. 1999, 35, 89-99. 
(14) Chesne, A. Du; Gerharz, B.; Lieser, G. The Segregation of Surfactant upon Film Formation of Latex Dispersions: An Investigation by Energy Filtering Transmission Electron Microscopy. Polym. Int. 1997, 43, 187-196.

(15) Hu, S.; Rieger, J.; Lai, Y.; Roth, S. V; Gehrke, R.; Men, Y. In-Situ Observation of Drying Process of a Latex Droplet by Synchrotron Small-Angle X-Ray Scattering. Macromolecules. 2008, 41, 5073-5076.

(16) Hu, S.; Rieger, J.; Yi, Z.; Zhang, J.; Chen, X.; Roth, S. V.; Gehrke, R.; Men, Y. Structural Evolution of a Colloidal Crystal Fiber during Heating and Annealing Studied by in Situ Synchrotron Small Angle X-Ray Scattering. Langmuir. 2010, 26, 13216-13220.

(17) Chen, X.; Fischer, S.; Yi, Z.; Boyko, V.; Terrenoire, A.; Reinhold, F.; Rieger, J.; Li, X.; Men, Y. Structural Reorganization of a Polymeric Latex Film during Dry Sintering at Elevated Temperatures. Langmuir. 2011, 27, 8458-8463.

(18) Joanicot, M.; Wong, K.; Cabane, B. Interdiffusion in Cellular Latex Films. Macromolecules. 1996, 29, 4976-4984.

(19) Belaroui, F.; Cabane, B.; Dorget, M.; Grohens, Y.; Marie, P.; Holl, Y. Small-Angle Neutron Scattering Study of Particle Coalescence and SDS Desorption during Film Formation from Carboxylated Acrylic Latices. J. Colloid Interface Sci. 2003, 262, 409-417.

(20) Aguirreurreta, Z.; de la Cal, J. C.; Leiza, J. R. Preparation of High Solids Content Waterborne Acrylic Coatings Using Polymerizable Surfactants to Improve Water Sensitivity. Prog. Org. Coatings. 2017, 112, 200-209.

(21) Aguirreurreta, Z.; Dimmer, J. A.; Willerich, I.; Leiza, J. R.; de la Cal, J. C. Improving the Properties of Water-Borne Pressure Sensitive Adhesives by Using Non-Migratory Surfactants. Int. J. Adhes. Adhes. 2016, 70, 287-296. 
(22) Canning, S. L.; Smith, G. N.; Armes, S. P. A Critical Appraisal of RAFT-Mediated Polymerization-Induced Self-Assembly. Macromolecules. 2016, 49, 1985-2001.

(23) Lansalot, M.; Rieger, J.; D’Agosto, F. Polymerization-Induced Self-Assembly: The Contribution of Controlled Radical Polymerization to The Formation of Self-Stabilized Polymer Particles of Various Morphologies. In Macromolecular Self-assembly; John Wiley \& Sons, Inc., 2016; pp 33-82.

(24) Jennings, J.; He, G.; Howdle, S. M.; Zetterlund, P. B. Block Copolymer Synthesis by Controlled/Living Radical Polymerisation in Heterogeneous Systems. Chem. Soc. Rev. 2016, 45, 5055-5084.

(25) Velasquez, E.; Pembouong, G.; Rieger, J.; Stoffelbach, F.; Boyron, O.; Charleux, B.; D’Agosto, F.; Lansalot, M.; Dufils, P. E.; Vinas, J. Poly(Vinylidene Chloride)-Based Amphiphilic Block Copolymers. Macromolecules. 2013, 46, 664-673.

(26) Lesage De La Haye, J.; Martin-Fabiani, I.; Schulz, M.; Keddie, J. L.; D 'agosto, F.; Lansalot, M. Hydrophilic MacroRAFT-Mediated Emulsion Polymerization: Synthesis of Latexes for Cross-Linked and Surfactant-Free Films. Macromolecules. 2017, 50, 9315-9328.

(27) Martín-Fabiani, I.; Lesage de la Haye, J.; Schulz, M.; Liu, Y.; Lee, M.; Duffy, B.; D’Agosto, F.; Lansalot, M.; Keddie, J. L. Enhanced Water Barrier Properties of Surfactant-Free Polymer Films Obtained by MacroRAFT-Mediated Emulsion Polymerization. ACS Appl. Mater. Interfaces. 2018, 10, 11221-11232.

(28) Chenal, M.; Rieger, J.; Véchambre, C.; Chenal, J.-M.; Chazeau, L.; Creton, C.; Bouteiller, L. Soft Nanostructured Films with an Ultra-Low Volume Fraction of Percolating Hard Phase. Macromol. Rapid Commun. 2013, 34, 1524-1529.

(29) Velasquez, E.; Rieger, J.; Stoffelbach, F.; D’Agosto, F.; Lansalot, M.; Dufils, P.-E.; Vinas, 
J. Surfactant-Free Poly(Vinylidene Chloride) Latexes via One-Pot RAFT-Mediated Aqueous Polymerization. Polymer. 2016, 106, 275-284.

(30) Lesage de la Haye, J.; Martin-Fabiani, I.; Schulz, M.; Keddie, J. L.; D’Agosto, F.; Lansalot, M. Hydrophilic MacroRAFT-Mediated Emulsion Polymerization: Synthesis of Latexes for Cross-Linked and Surfactant-Free Films. Macromolecules. 2017, 50, 9315-9328.

(31) http://www.mantidproject.org.

(32) Wignall, G. D; Bates, F. S. Absolute Calibration of Small-Angle Neutron Scattering Data. J. Appl. Crystallogr. 1987, 20, 28-40.

(33) http://www.sasview.org/.

(34) Tatsumi, R.; Iwao, T.; Koike, O.; Yamaguchi, Y.; Tsuji, Y. Effects of the Evaporation Rate on the Segregation in Drying Bimodal Colloidal Suspensions. Appl. Phys. Lett. 2018, 112, 053702 .

(35) Rösler, M. A.; Klinke, E.; Kunz, G. Evaporation of Solvents by Infrared Radiation Treatment. Prog. Org. Coatings. 1994, 23, 351-362.

(36) Narita, T.; Hébraud, P.; Lequeux, F. Effects of the Rate of Evaporation and Film Thickness on Nonuniform Drying of Film-Forming Concentrated Colloidal Suspensions. Eur. Phys. J. E 2005, 17, 69-76.

(37) Carter, F. T.; Kowalczyk, R. M.; Millichamp, I.; Chainey, M.; Keddie, J. L. Correlating Particle Deformation with Water Concentration Profiles during Latex Film Formation: Reasons That Softer Latex Films Take Longer to Dry. Langmuir. 2014, 30, 9672-9681.

(38) Sperry, P. R.; Snyder, B. S.; O’Dowd, M. L.; Lesko, P. M. Role of Water in Particle Deformation and Compaction in Latex Film Formation. Langmuir. 1994, 10, 2619-2628.

(39) Jacob N. Israelachvili. Intermolecular and Surface Forces, 2nd Ed.;Academic Press: 
London, 1992, 3rd ed.; Academic Press: London, 1992.

(40) Domingues, F.; Santos, D. O. S.; Leibler, L. Large Deformation of Films from Soft-Core / Hard-Shell. 2002, pp 224-234.

(41) Steinhaus, H. Mathematical Snapshots, 3rd ed.; Dover: New York, 1999.

(42) Nawaz, Q.; Rharbi, Y. Various Modes of Void Closure during Dry Sintering of ClosePacked Nanoparticles. Langmuir. 2010, 26, 1226-1231.

(43) Joanicot, M.; Wong, K.; Richard, J.; Maquet, J.; Cabane, B. Ripening of Cellular Latex Films. Macromolecules. 1993, 26, 3168-3175.

(44) Jones, R. A. L. Soft Condensed Matter; Oxford University Press, 2002. 


\section{TABLE OF CONTENTS}

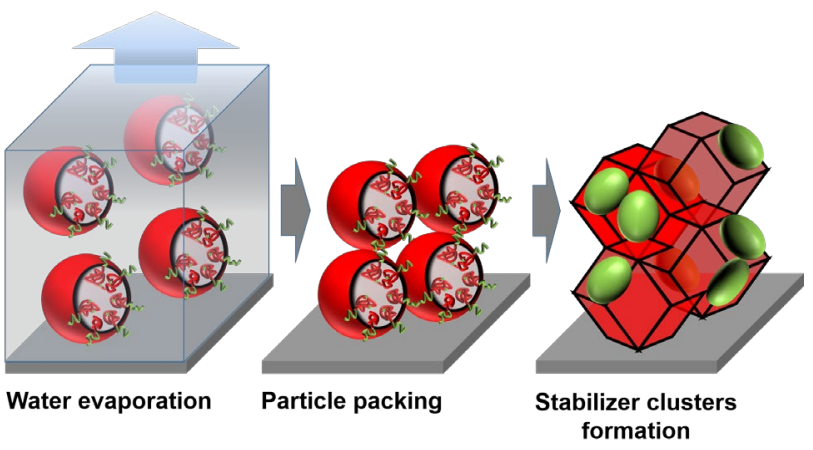

